\title{
Investigate the Effect of Pitch Variations on Helically Coiled Pipe for Laminar Flow Region Using CFD
}

\author{
Anwer F. Faraj ${ }^{1}$, Itimad D.J. Azzawi ${ }^{2 *}$, Samir G. Yahya ${ }^{2}$ \\ ${ }^{1}$ University of Manchester, Ministry of Oil, Iraqi Drilling Company, Diyala 32001, Iraq \\ ${ }^{2}$ Mechanical Engineering Department, Faculty of Engineering, University of Diyala, Diyala 32001, Iraq
}

Corresponding Author Email: itimaddawood_eng@uodiyala.edu.iq

https://doi.org/10.18280/ijht.380221

Received: 1 March 2020

Accepted: 28 May 2020

\section{Keywords:}

CFD, helical coil, friction factor, Reynolds number, pitch size

\begin{abstract}
Experimental investigations of the flows inside helically coiled pipe are difficult and may also be expensive, particularly for small diameters. Computational fluid dynamics (CFD) packages, which can easily construct the geometry and change the dimensions with $100 \%$ of accuracy, provide an alternative solution for the experimental difficulties and uncertainties. Therefore, a computational fluid dynamics (CFD) study was conducted to analyse the flow structure and the effect of varying the coil pitch on the coil friction factor and wall shear stress, through utilising different models' configurations. Three coils were tested, all of them sharing the same pipe and coil diameter: $0.005 \mathrm{~m}$ and $0.04 \mathrm{~m}$ respectively. Pitch variations began with $0.01,0.05,0.25 \mathrm{~m}$ for the first, second and third model respectively. In this study, the pressure drop was analysed, and the effects of this reduction on wall shear stress and coil friction factor were also examined using incompressible viscous laminar flow to elucidate the effect of varying coil pitch on the friction factor and wall shear stress. The results were validated by Ito's equation for the laminar flow and compared with the Hagen-Poiseuille resistance formula for a straight pipe.
\end{abstract}

\section{INTRODUCTION AND PREVIOUS LITERATURE RELATED}

Flows in curved pipes receive the attention of many researchers due to their practical significance in a wide range of many engineering applications such as nuclear reactors, air conditioning systems, and heat exchangers. The accumulation of published papers is increasing in both computational fluid dynamics (CFD) and experimental methodologies. Flows following a curved path induce a centrifugal force which pushes the faster fluid particles outwards, whereas the slower ones are pushed inwards; and since the centrifugal force depends on the local axial velocity, therefore the slower particles suffer a lower centrifugal effect while the faster ones experience higher centrifugal forces [1]. The imbalance in the centrifugal forces develops a secondary flow which ends with two-counter rotating vortices called Dean Vortices as shown in Figure 1 [2]. The secondary flow, in turn, increases flow mixing which consequently increases the rate of heat transfer in comparison with a straight pipe.

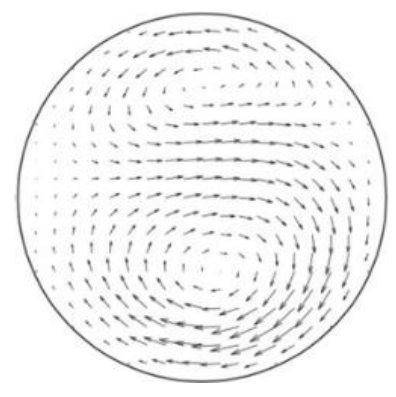

Figure 1. Dean vortices [3]
Moreover, the controlling parameters in helically coiled pipes are curvature ratio $(\delta)$, Reynolds number (Re), Dean number $(\mathrm{De})$, Torsion parameter $\left(\beta_{0}\right)$ and pitch size and the calculating formula for each parameter is available in the study [4] and not repeated here. Figure 2 defines these parameters especially the distance between the centerline of two turns.

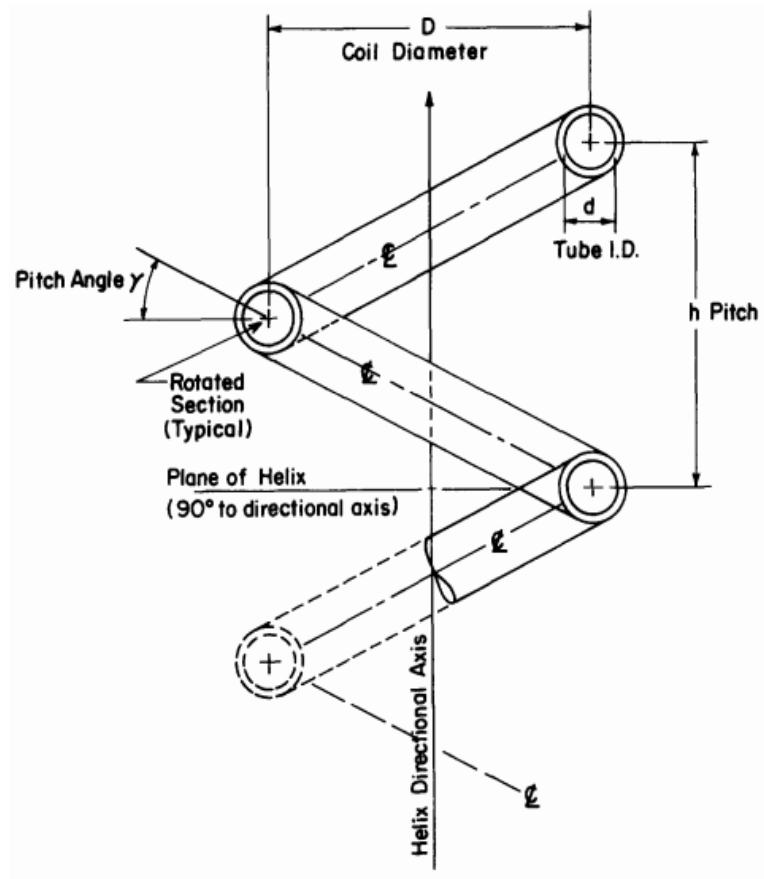

Figure 2. The parametric explanation of a helically coiled pipe [4] 
The following section presents an outline of selected research papers investigating laminar flows in a helically coiled pipe. Both experimental findings and computational fluid dynamics (CFD) techniques will be studied and analysed for the different parameters which have a direct effect on the secondary flow formulation, such as Dean Number, curvature ratio, pitch size and pipe diameter, and the effect of these parameters on the rate of heat transfer. In this section, attention will be paid to the flow structure particularly in a fully developed region in terms of pressure drop, pitch size, and curvature ratio, which plays a leading role in the determination of wall shear stress and consequently the coil friction factor. It has been widely reported that the rate of heat transfer in helically coiled pipes is substantially larger than in straight pipes. However, there is a lack of information concerning the deep understanding of the flow structure inside helically coiled pipes. Jayakumar et al. studied and analysed the changes of local Nusselt number along the length and perimeter of helical pipes using CFD [5]. It has been found that the turbulent intensity at the outer side becomes around $13.4 \%$ higher than its equivalent on the inner side. The effect of pitch circle diameter was analysed by Jayakumar [6]. Three coils were tested while keeping the pitch and the diameter of the pipe constant. It was found that the pitch circle diameter has a direct influence on flow structure and hence the secondary flow structure across the pipe. Jayakumar stated that the pitch circle diameter is inversely proportional to the centrifugal forces, i.e. as the pitch circle diameter increases the effect of the centrifugal forces on the flow structure will be impaired [6]. In a fully developed region, a correlation has been formulated to relate the average Nusselt number to the curvature ratio which indicates that the average Nusselt number decreases as the pitch circle diameter decreases while keeping the pipe diameter constant as shown in Eq. (1) below.

$$
\mathrm{Nu}=265.65(\delta)^{0.11}
$$

From the heat transfer perspective, the rate of heat transfer was mainly acquired by using two approaches: firstly, from the production of the water mass flux and the increment of the temperature. Secondly, the productions of condensate mass flux and the variation of specific enthalpy. The percentage of error was never exceeding $₹ 3 \%$. Rogers and Mayhew used Eq. (2) [7], proposed by Wilson, and Kreith and Margolis [8, 9] to determine the overall heat transfer coefficient (U).

$$
Q=U \log \text { mean } \Delta t
$$

where,

$$
\Delta t=\frac{\left(t_{g}-t_{b 1}\right)-\left(t_{g}-t_{b 2}\right)}{\operatorname{Ln} \frac{\left(t_{g}-t_{b 1}\right)}{\left(t_{g}-t_{b 2}\right)}}
$$

A comparison has been made with Kirpikov's findings with different curvature ratios to calculate the heat transfer rate [10]. In Figure 3, it can be seen that using Kirpikov's relationship shown in Eq. (3), to denote the y-axis in Figure 3, with different curvature ratio does not make a large difference in terms of heat transfer rate as clearly seen in Figure 3.

Bai et al. did an experiment to find the most appropriate correlation for measuring the average heat transfer coefficient at different cross-sections of a helically coiled pipe [11]. Although many investigations had been done previously by [7,
$12,13]$ for the same reason mentioned above, it was still necessary to establish a correlation which would cover a wide range of horizontal helically coiled pipes and to gain a more profound comprehension of the local heat transfer attributes in both axially and circumferential directions.

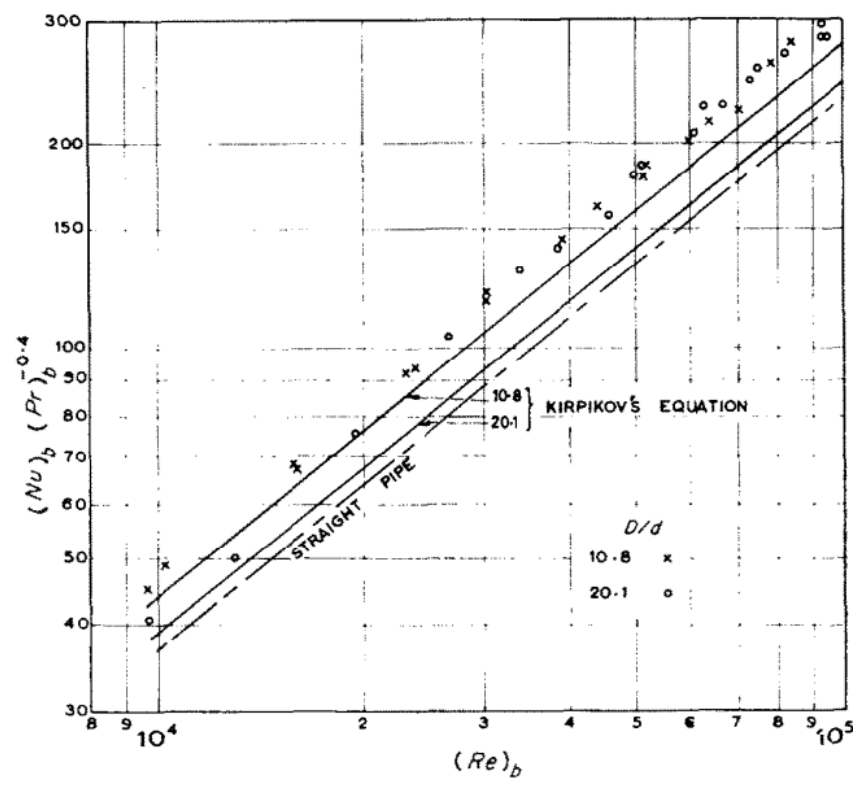

Figure 3. Heat transfer findings, properties evaluated at bulk temperature [7]

$$
(N u)\left(P r^{-0.4}\right)=0.0456\left(R e^{0.8}\right)\left(\frac{d}{D}\right)^{0.21}
$$

This equation has been compared with many different equations to show the enhancement in the prediction of the average heat transfer coefficient. It has been concluded that, as Reynolds number increases, the turbulent boundary layer becomes less thick and this, in turn, reduces the contribution of the secondary flow to improve the rate of heat transfer. Furthermore, the profile of the average heat transfer coefficient on the circumferential cross-section of the pipe is roughly symmetrical.

Turning to discuss the influence of pitch variation, when the pitch is zero, that means there is no torsional effect on the flow; consequently, the only force which affects on the flow is the centrifugal force. Therefore, as the pitch increases the average Nusselt number increases as well [6]. In terms of pipe diameter, Jayakumar conducted a regression analysis to find the relationship between the pipe diameter and the average Nusselt number [6]. It was found that there is a linear relationship between the average Nusselt number and the pipe diameter. Yamamoto et al. investigated the implications of changing the curvature ratio and the torsional effect on the flow structure using the spectral method [14]. The same author was represented different secondary flow structures at different Reynolds numbers and specific $\beta_{0}$ where the number next to each photo denotes Torsion parameter as shown in Figure 4. It can notice that when Reynolds number has a small value, the secondary flow is small as well. However, as Reynolds number increases, the two vortices become clearer. These results confirmed the results of Yamamoto et al. [15].

Four coils were used to study and analyse the effect of varying the pitch on the flow structure and hence, the effect of that on the rate of heat transfer in laminar flow. It was found that the laminar flow in helically coiled pipes extends 
substantially more to high Reynolds number in comparison with a straight pipe and therefore, the difference in the rate of heat transfer is much more noticeable in laminar regions and for that reason, this became an extensive research area [17]. In terms of the heat transfer, the average Nusselt number for the helically coiled pipe of the Austen and Soliman [17] experiment was compared with the results of Siegel et al. for the straight pipe [18]. Not surprisingly, the rate of heat transfer was greatly exceeding that of a straight pipe for any Reynolds number.

There is a noticeably greater increase in the rate of heat transfer when the pitch of the coil is high for a relatively small Reynolds number. This statement is supported by Manlapaz and Churchill [19] and Abul-Hamayel [20], but the latter added that when the pitch of the coil is low with upward feeding. Seban and McLaughlin found that the heat transfer coefficient of the coil external surface is much larger than the internal. These heat transfer coefficients greatly surpassed those of the straight pipe [12].

Experimental investigations of the flows inside helically coiled pipe are difficult and may also be expensive, particularly for small diameters. Deformations can occur during the manufacturing process, which causes ovality and consequent uncertainty in measuring the internal diameter up to $0.25 \%$ and may give an elliptic cross-section instead of circular [1]. Computational fluid dynamics packages provide an alternative solution for experimental difficulties and uncertainties. This allows the researcher an opportunity to study and analyse different geometric configurations and facilitates changing the laminar flow type regime. As a result of the above, the objectives of this research are to study and investigate the flow structure inside helically coiled pipes for three different pitch sizes: $(0.01,0.05$, and 0.25$) \mathrm{m}$ through analyzing the velocity-pressure contours in addition to velocity vectors. Moreover, evaluate the coil friction factor and wall shear stress in comparison with Ito's equation for a small pitch and Hagen-Poiseuille, Filonenko resistance formulas for laminar flow. Moreover, the turbulent flow was examined, it's not presented in this research (omitted for brevity) since it needs two turbulent models at least such as, the STD $(k-w)$ and the STD $(k-\epsilon)$ models and therefore it shall be considered for future studies and publication.

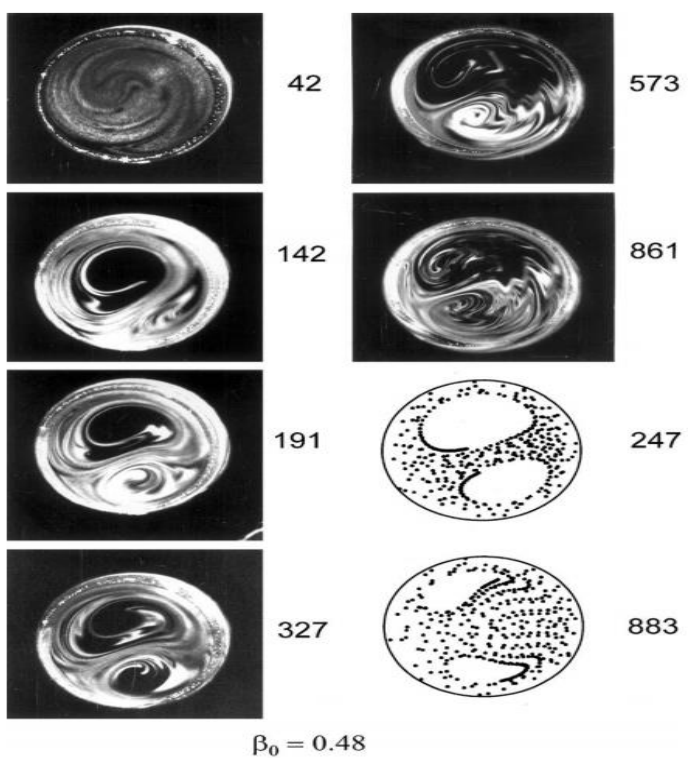

Figure 4. Secondary flow photos when $\beta[0=0.48[16]$

\section{MODEL DESCRIPTION AND METHODOLOGY}

Three models of horizontally oriented helically coiled pipe have been utilised with two turns, to ensure that flow reaches a fully developed region [21] and different pitches as shown in Figure 5. The diameter and inclination of the spiral tube are ignored in this research since it's been widely studied and it's still a research area to find the perfect angle which can give a higher intensity of secondary flow in comparison with the horizontal and vertical oriented helical coil.

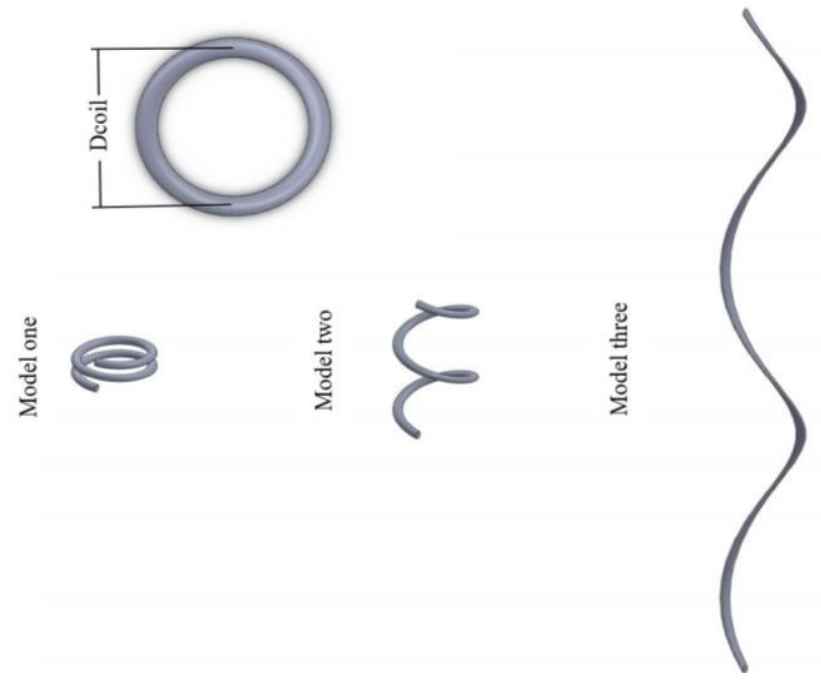

Figure 5. Models geometry plotted in 2:1 scale

The pipe and coil diameters are taken respectively as $\mathrm{d}=0.005 \mathrm{~m}$, Dcoil $=0.04 \mathrm{~m}$ with different pitches $\mathrm{P}=(0.01,0.05$, and 0.25 ) $\mathrm{m}$ as shown in Table 1 .

Table 1. Models dimensions

\begin{tabular}{cccc}
\hline Models & $\begin{array}{c}\text { Pipe diameter } \\
\text { (d)m }\end{array}$ & $\begin{array}{c}\text { Coil diameter } \\
\text { (Dcoil)m }\end{array}$ & $\begin{array}{c}\text { Pitch (P) } \\
\text { m }\end{array}$ \\
\hline $\begin{array}{c}\text { Model } \\
\text { one }\end{array}$ & 0.005 & 0.04 & 0.01 \\
$\begin{array}{c}\text { Model } \\
\text { two }\end{array}$ & 0.005 & 0.04 & 0.05 \\
$\begin{array}{c}\text { Model } \\
\text { three }\end{array}$ & 0.005 & 0.04 & 0.25 \\
\hline
\end{tabular}

In Table 1, the pipe and coil diameters are constants, but the pitch is different. The second and third models are designed to explore the effect of a varying pitch on the secondary flow structure. The two vortices are symmetrical if the pipe is bent in a toroidal shape, but if the bent in a helical shape the symmetry breaks up [1]. Stretching helically coiled pipe while keeping the pipe and coil diameter constant needs an increment in the helix length. The helix length of the three models has been calculated with a very simple basic equation derived from Pythagoras-theorem as shown below [22]:

$$
\begin{gathered}
\text { helix length }=\left[(\text { Coil circumference })^{2}\right. \\
\left.+(\text { Pitch })^{2}\right]^{1 / 2} \times N
\end{gathered}
$$

where: $\mathrm{N}=$ number of turns.

Moreover, two surfaces were defined in the geometry in a fully developed region: specifically, in the last quarter of the helically coiled pipe before the outlet, as shown in Figure 6. Plane two is located well downstream of the inlet to guarantee 
fully developed flow conditions; one coil turn is enough to assure fully developed flow [15], while plane one is located near the outlet, to avoid the processed arrangement of being influenced by the outlet boundary conditions. The purpose of these two planes is to evaluate the average pressure at each plane, then compute the pressure difference in order to obtain the wall shear stress in a fully developed area.

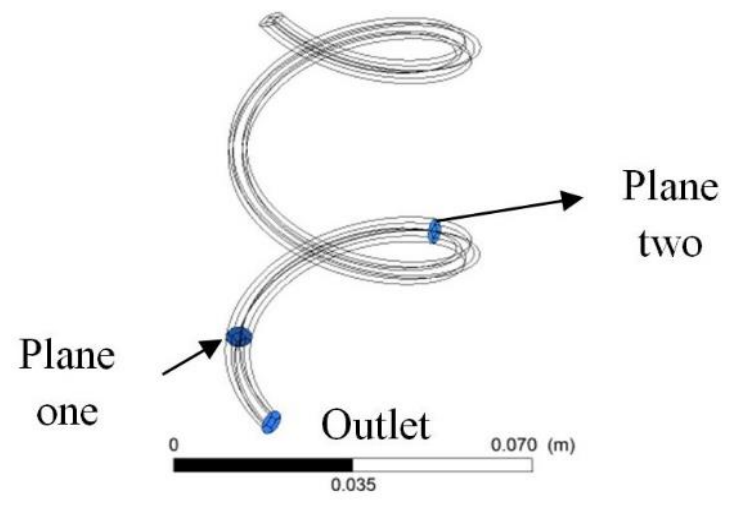

Figure 6. Positions of planes for $\mathrm{P}=0.05 \mathrm{~m}$

\subsection{Computational Domain and Solution Procedure}

A comparison has been made between the one-domain automatic generated and five-domain $\mathrm{O}-\mathrm{H}$ grid method "butterfly topology" mesh as shown in Figures 7-a to 7-c. It has been found that ordinary automatic generated mesh has considerable skewness particularly near the wall which is considered an important region, especially when studying the near-wall behaviour (Figure 7-a). In Figures7-b, when the five-domain $\mathrm{O}-\mathrm{H}$ grid method "butterfly topology" mesh is applied, greater reduction in the maximum included angle is obtained i.e. the maximum included angle is reduced from $175.35^{\circ}$ to $130.2^{\circ}$, which helps to increase the stability and accuracy of the solution. After selecting Grid-solver and running the solver, the maximum included angle is decreased again to $124.8^{\circ}$ and most of the cells become orthogonal. The percentage of cells with an angle of $121^{\circ}-124^{\circ}$ does not exceed $10 \%$ of the total cells, as shown in Figures 7-c, and this mesh may be considered the best mesh which can capture most of the flow characteristics.

To obtain a grid-independent solution, different simulations were run with different mesh arrangements. Four cases of mesh: coarse $(95,956$ cells), medium $(185,623$ cells $)$, fine $(313,823$ cells $)$ and very fine mesh $(597,600$ cells $)$, as shown in Figure 8 (see Table 2 for further details), were studied and analysed to choose an adequate mesh which gives acceptable results with minimum errors and computer resources in addition to a satisfactory computational time.

Table 2 showed that the mesh has been used with different numbers of cells to acquire a mesh independent solution. It can be seen that there is no great difference in maximum velocity in all types of mesh i.e. all of them have the same difference of 0.001 . However, the difference between the very fine mesh and the coarse is 0.003 . To attain the most appropriate mesh which can capture most of the flow characteristics, one may need to choose the mesh where there is no difference in results as the mesh size is increased. The medium mesh gives satisfactory results in addition to saving computational time and reducing the requirement for computer resources because of the large difference in cell numbers between the medium and very fine mesh, which leads to a small difference in the findings. For the above reasons, the medium mesh has been chosen to simulate the three models. Moreover, the mesh study using the maximum velocity has been validated by using the values of CFD Fanning friction factor with different cell numbers. It has been found that the difference in CFD Fanning friction factor between the medium and fine mesh is quite low (0.001), which makes it unnecessary to increase the mesh size if the difference is ignorable. Hence, the fine mesh has been chosen in the simulation.
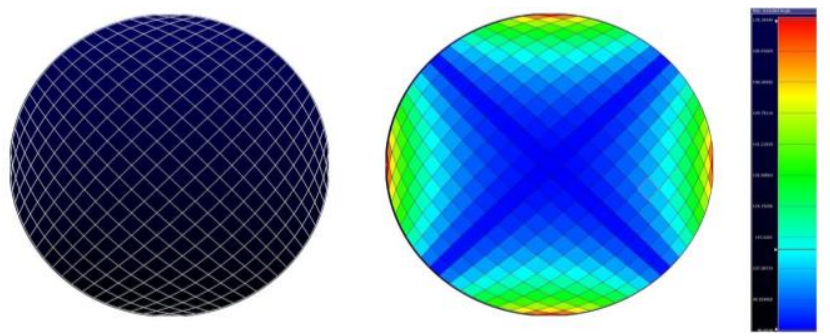

(a)
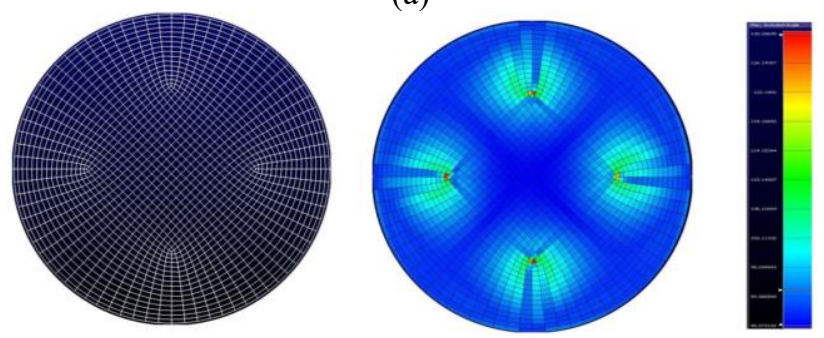

(b)
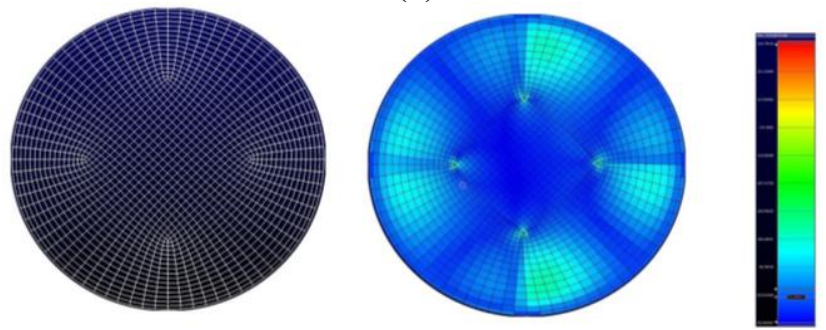

(c)

Figure 7. The one (a) to five (c) domain automatic generated mesh with the maximum included angle
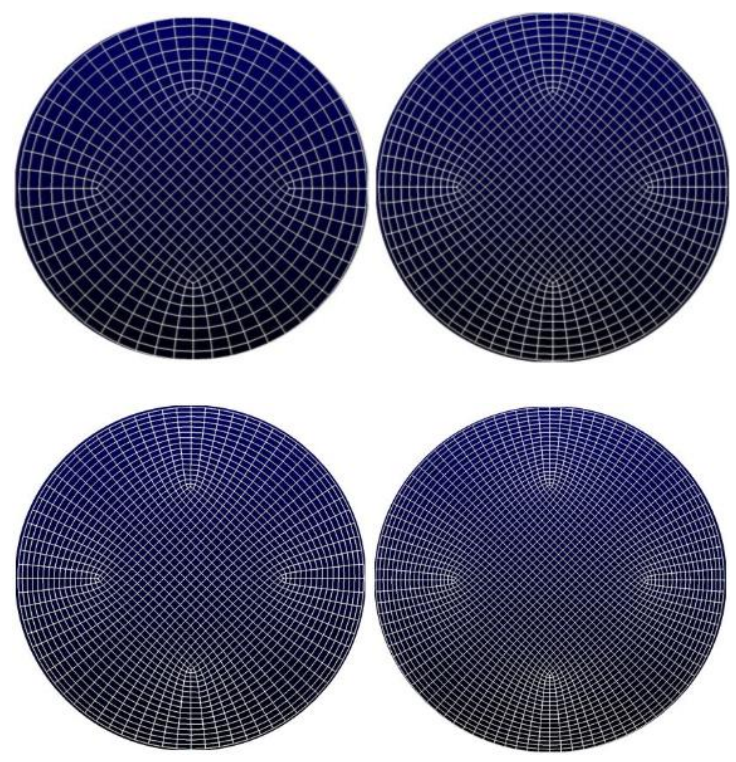

Figure 8. Mesh generation from coarse to very fine mesh 
Table 2. Different mesh arrangements with their number of cells, maximum velocity and friction factor

\begin{tabular}{cccc}
\hline Mesh type & Total mesh & $\begin{array}{c}\text { Maximum } \\
\text { velocity }\end{array}$ & $\begin{array}{c}\text { Friction } \\
\text { factor }\end{array}$ \\
\hline $\begin{array}{c}\text { Coarse mesh } \\
\text { Medium } \\
\text { mesh }\end{array}$ & 95,956 & 0.174 & 0.053393 \\
$\begin{array}{c}\text { Fine mesh } \\
\text { Very fine } \\
\text { mesh }\end{array}$ & 313,823 & 0.176 & 0.065634 \\
\hline
\end{tabular}

\section{GOVERNING EQUATIONS AND CORRELATION COMPARISON}

The governing equations applied to the models to calculate the friction factor and wall shear stress are available in the researches $[1,23]$ and not repeated here. However, in a fully developed region, i.e. when the velocity gradient is constant, the wall shear stress can be computed from the static pressure drop over a determined length of pipe [1]. There are many experimental equations which can be used to predict the friction factor and the pressure in a helically coiled pipe, for instance [24-31]. All of these present an acceptable agreement between their correlations since Ali has made a comparison between the aforementioned correlations which gave almost convergent results [15].

Ito's equations have been adopted in the calculations because they are practical and easy to implement. Furthermore, this is the most accurate formula [32]. On the other hand, White's equations do not work with the model's dimensions since they are limited to $\mathrm{De}<11.6$ and $\operatorname{Re}<100,000$. Mori equation is complicated while Misra and Gupta's equations used what is called $(\mathrm{He})$ helical number which made the equations drastically complicated and limited. For the above reasons, Ito's equations have been chosen to compute the coil friction factor.

The governing equations applied to the models to calculate the friction factor and wall shear stress are listed below:

The dimensionless Fanning friction factor [1]:

$$
f_{\text {straight }}=\frac{\tau_{\mathrm{w}}}{\frac{1}{2} \rho^{2}}
$$

Fanning friction factor for straight pipe laminar flow [1]:

$$
f_{\text {straight }}=\frac{16}{\mathrm{R}_{\mathrm{e}}}
$$

Ito's coil friction factor for laminar flow [1]

$$
f_{\text {coil }}=\frac{344\left(\frac{\mathrm{D}_{\text {coil }}}{\mathrm{d}}\right)^{-0.5}}{\left\{1.56+\log _{10}\left[\mathrm{R}_{\mathrm{e}}\left(\frac{\mathrm{D}_{\text {coil }}}{\mathrm{d}}\right)^{-0.5}\right]\right\}^{5.73}}
$$

Ensuring that

$$
\begin{aligned}
13.5\left(\frac{D_{\text {coil }}}{d}\right)^{0.5} \leq & R_{e} \\
& \leq 2000\left[1+13.2\left(\frac{D_{\text {coil }}}{d}\right)^{-0.6}\right] \cup 5 \\
& \leq\left(\frac{D_{\text {coil }}}{d}\right) \leq 2000
\end{aligned}
$$

In a fully developed region, i.e. when the velocity gradient is constant, the wall shear stress can be computed from the static pressure drop over a determined length of pipe [1].

$$
\text { wall shear stress }=\frac{\text { Force }}{\text { Area }}=\frac{\Delta \mathrm{p} \times \pi \mathrm{R}^{2}}{2 \pi \mathrm{R} \times \mathrm{dx}}=\frac{\mathrm{R}}{2} \times \frac{\Delta \mathrm{p}}{\mathrm{dx}}
$$

\subsection{Boundary condition and solution method}

The boundary conditions for the helically coiled pipe simulation were set as water domain fluid with laminar flow velocity inlet condition. Seven Reynolds numbers (from 500 to 2000 with 250 increments) were used in the simulation i.e. different velocity values were set at the inlet for each pitch to examine the flow structure as the pitch changed. Moreover, the wall is taken as a stationary wall and the no-slip condition is applied to the wall, while the outlet is taken as a pressure outlet.

Pressure based solver was chosen for the helically coiled pipe simulation since it is generally used for the incompressible fluid. The SIMPLE [Semi-Implicit Method for Pressure-Linked Equations] algorithm by Patankar et al. was used in order to discretise the velocity field through the solution of the momentum equation [33]. The Green-Gauss cell-based theorem was set to evaluate the scalars at the cell centroid.

\section{RESULTS AND DISCUSSION}

Here, only the most significant data on the helically coiled pipe through utilising three different models are presented. Generally, the flows inside a helically coiled pipe are controlled by three parameters: pitch size, curvature ratio, and Dean Number. In this study, the effect of the curvature ratio has not been analysed, since the pipe and coil diameter is constant. A range of different Reynolds numbers has been taken. Since the variations of Dean Number and pitch size has a direct influence on flow structure, the effect of decreasing or increasing Dean number and pitch size on the coil friction factor, wall shear stress, and velocity-pressure contours will be presented.

Figure 9 shows the trend of the friction factor in a helically coiled pipe in addition to the Hagen-Poiseuille resistance formula for the straight pipe. In all cases, i.e. for both straight and helically coiled pipe, the trend indicates that there is an inverse proportion between friction factor and Reynolds number; i.e. as Reynolds number increases, the friction factor is reduced, due to the fact that the friction factor is inversely proportioned to the average flow velocity. Ito stated that the experimental procedure is accomplished by using only one coil turn since this is sufficient to guarantee a fully developed flow; consequently, Ito's equation is only applicable for helically coiled pipe with a small pitch [16].

For $\mathrm{P}=0.01 \mathrm{~m}$, the simulations yield an acceptable result, where the difference between the experimental and the numerical result does not exceed $0.9 \%$ in all Reynolds numbers. Since there are no experimental equations for $\mathrm{P}=0.05 \mathrm{~m}$ or $0.25 \mathrm{~m}$, and the simulation findings for $\mathrm{P}=0.01 \mathrm{~m}$ have been validated with Ito's equation (1959), the simulation is continued for the laminar flow, noting that the coil friction factor for $\mathrm{P}=0.05 \mathrm{~m}$ and $0.25 \mathrm{~m}$ should not be higher than the equivalent for $\mathrm{P}=0.01 \mathrm{~m}$ and not less than the friction factor for the straight pipe. 


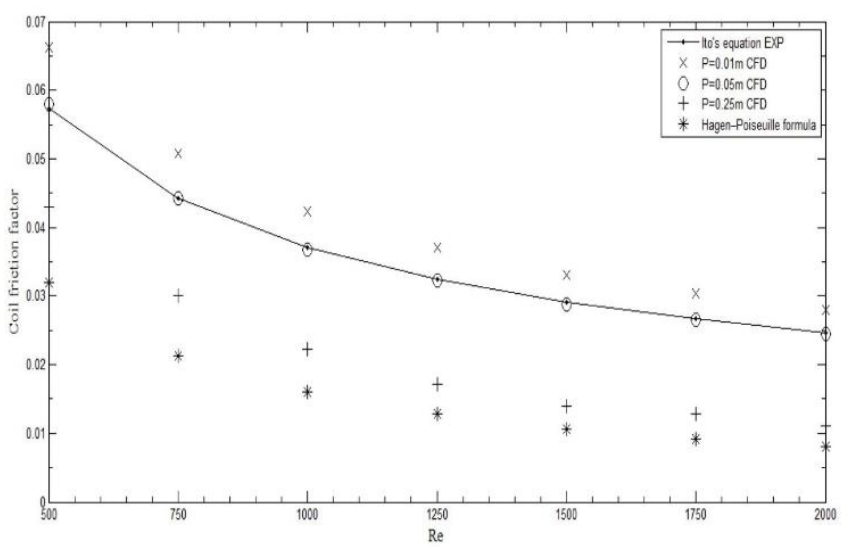

Figure 9. Coil friction factor versus Reynolds number

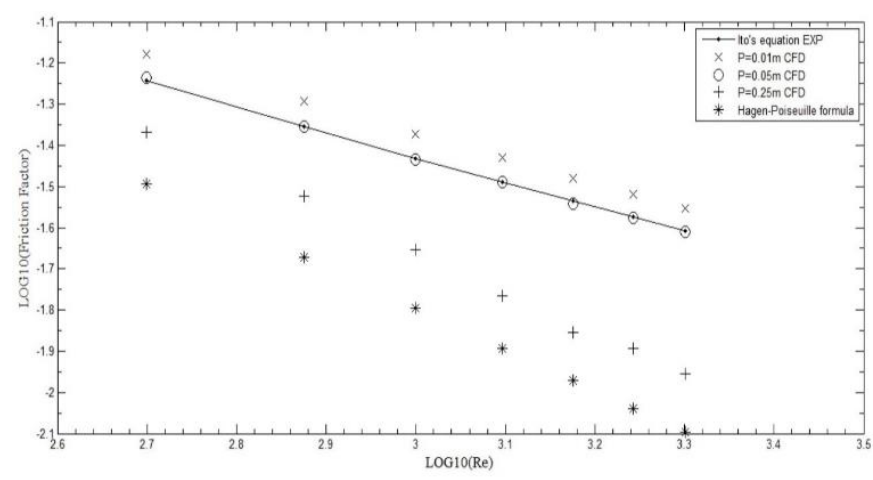

Figure 10. $\log 10$ (Friction factor) versus $\log 10(\mathrm{Re})$

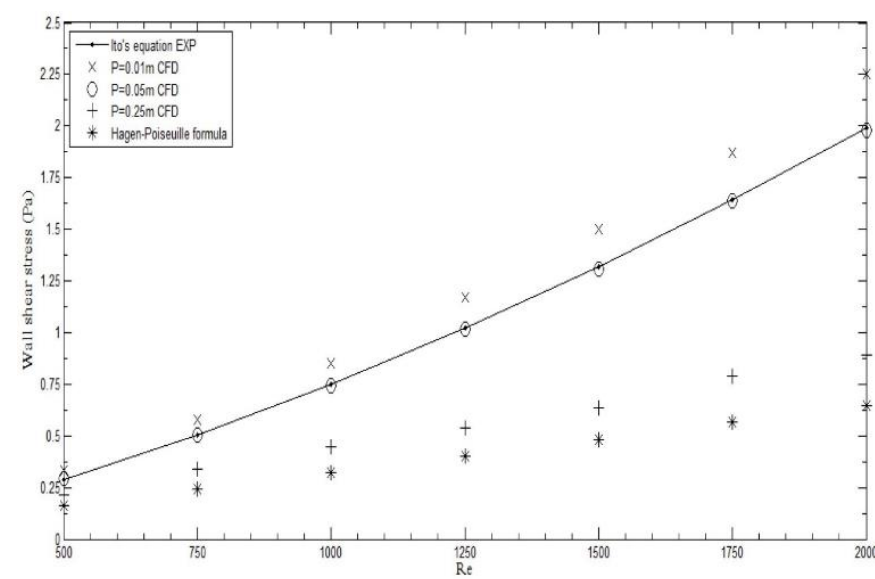

Figure 11. Wall shear stress versus Reynolds number

For $\mathrm{P}=0.05 \mathrm{~m}$, the friction factor values appear to be typical for Ito's equation and this may seem wrong because the friction factor for $\mathrm{P}=0.05 \mathrm{~m}$ should not be almost the same as Ito's equation if the latter can only be used with a small pitch. Ito's equation is characterised only by Reynolds number and $\left(\frac{D_{\text {coil }}}{d}\right)$; i.e. if the term $\left(\frac{D_{\text {coil }}}{d}\right)$ is constant and the same Reynolds number is being used to evaluate the coil friction factor for a different pitch configuration, it will give the same result for the coil friction factor whatever pitch is employed and this is incorrect.

There is no sufficient information in the literature to explain precisely the pitch limitations of Ito's equation; i.e. no one currently knows how small is small. Cioncolini and Santini (2006) investigated Ito's equation for different pitch configurations from $\mathrm{P}=0.007 \mathrm{~m}$ to $\mathrm{P}=0.025 \mathrm{~m}$ [1]. It was found that Ito's equation is applicable even for $\mathrm{P}=0.025 \mathrm{~m}$, although Ito's experiment was conducted using a toroidal pipe, and gives approximately a typical result in comparison with Cioncolini and Santini's experimental data. As a summary, the friction factor for $\mathrm{P}=0.05 \mathrm{~m}$ should not be compared with Ito's equation, because Ito's equation may also be applicable for $\mathrm{P}=0.05 \mathrm{~m}$ and hence give approximately the same result for the coil friction factor.

For $\mathrm{P}=0.25 \mathrm{~m}$, an abrupt decrease in the coil friction factor occurs as expected due to the greater drop of the pressure gradient in comparison with $\mathrm{P}=0.01 \mathrm{~m}$ and $\mathrm{P}=0.05 \mathrm{~m}$. The difference in coil friction factor values of $\mathrm{P}=0.25 \mathrm{~m}$ and HagenPoiseuille resistance formula for a straight pipe does not exceed $1 \%$ in all Reynolds numbers. The effect of the secondary flow becomes weaker due to the high reduction in the centrifugal forces which consequently reduces the wall shear stress and the coil friction factor since the latter is directly proportioned to the former. To make the slope of the friction factor clearer, the log-log plot has been taken into consideration to show the overall slope of the friction factor, as shown in Figure 10.

From Figure 10, it can be seen that the slope of the three models in addition to the experimental equations is almost constant, but it is a negative slope i.e. as the common logarithm of the Reynolds number increases, the common logarithm of the friction factor decreases.

Figure 11 indicates that the wall shear stress is directly proportioned to Reynolds number; i.e., whenever the Reynolds number increases the wall shear stress, is also increased. The non-uniformity in pressure distribution comes from the effect of the centrifugal forces which cause the secondary flow that occurs at the curved surfaces, resulting in variations in velocity distribution within the domain. The fluid particles at the pipe wall have slower velocities, because of the existence of the boundary layer, which also makes the applied centrifugal forces lower. As a result of this, a recirculating region is constructed. The maximum wall shear occurs at the outer edge of the pipe since this region experiences a greater centrifugal force; then it starts to reduce when the fluid particles begin to move inward to the inner side of the pipe.

Figure 12 below, introduces the velocity distribution in a fully developed region of the first plane for different Reynolds numbers. It can be seen that the minimum velocity lies near the wall due to the non-slip boundary conditions; the velocity of fluid particles starts to increase from the inner to the outer wall. The maximum velocity of the fluid particles should be in the centre of the pipe. However, the effect of the curved surfaces induces the centrifugal forces and causes the secondary flow, which in turn, forms Dean Vortices. Dean vortices are named after the British scientist Dean [34]. They consist of a pair of counter-rotating vortices which push the fluid particles that have higher velocities towards the outer edge of the pipe (as indicated clearly in Figure 12), consequently driving the slower ones towards the inner side of the pipe. This creates what is called non-uniformity in velocity distribution. Moreover, the velocity distribution becomes flattered as the Reynolds number increases, since the centrifugal force is directly proportional to flow velocity.

Figure 13 shows how the secondary flow develops with the aid of the flow streamlines. The streamlines deviate sharply from their path just after the inlet, since the first model has a small pitch almost like a toroidal pipe; and this rotation of the streamlines increases flow mixing and consequently also increases the wall shear stress. 


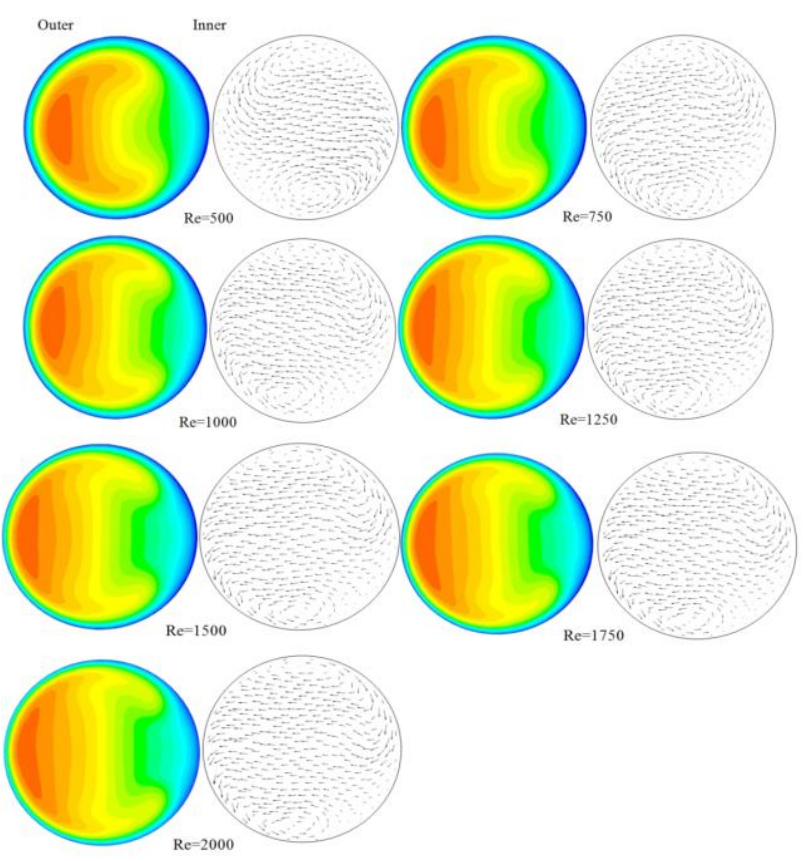

Figure 12. Velocity contours and vectors of the first plane for $\mathrm{P}=0.01 \mathrm{~m}$

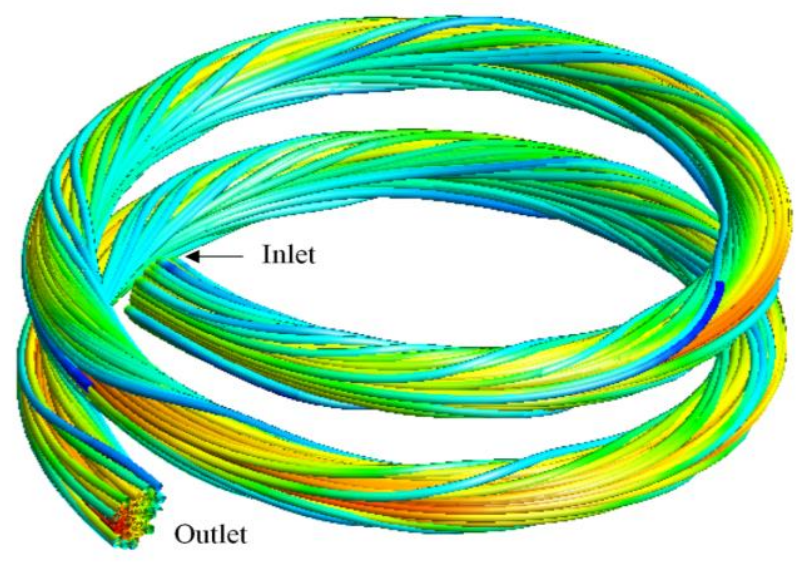

Figure 13. Flow streamlines for $\mathrm{P}=0.01 \mathrm{~m}$

Turning to discuss the velocity distribution of the second model $(\mathrm{P}=0.05 \mathrm{~m})$, at $\mathrm{Re}=500$ (as shown below in Figure 14$)$, the velocity contours look different in comparison with the other Reynolds numbers: the red colour which denotes the maximum velocity takes a large portion of the velocity distribution in comparison with its equivalent at $\mathrm{P}=0.01 \mathrm{~m}$. Furthermore, the overall form of the velocity contours appears to be more bent in comparison with other Reynolds numbers, because of the imbalance in the centrifugal forces, while the other velocity contours do not look very different from the equivalent for $\mathrm{P}=0.01$, which is indicated very clearly in Figure 12, where the difference between the friction factor of $\mathrm{P}=0.01 \mathrm{~m}$ and $\mathrm{P}=0.05 \mathrm{~m}$ does not exceed $0.8 \%$ in all cases. Accordingly, the effect of the centrifugal forces at $\mathrm{P}=0.05 \mathrm{~m}$ is slightly lower than $\mathrm{P}=0.01 \mathrm{~m}$.

From Figure 15, it can be seen that the flow streamlines take a longer stream path in comparison with the equivalent at $\mathrm{P}=0.01 \mathrm{~m}$. The reason is the increment in the pitch dimension, which in turn, plays a significant role in secondary flow formulation. Furthermore, the pressure gradients are affected by these streamlines which make the wall shear stress drop slightly in comparison with the first model $(\mathrm{P}=0.01 \mathrm{~m})$.
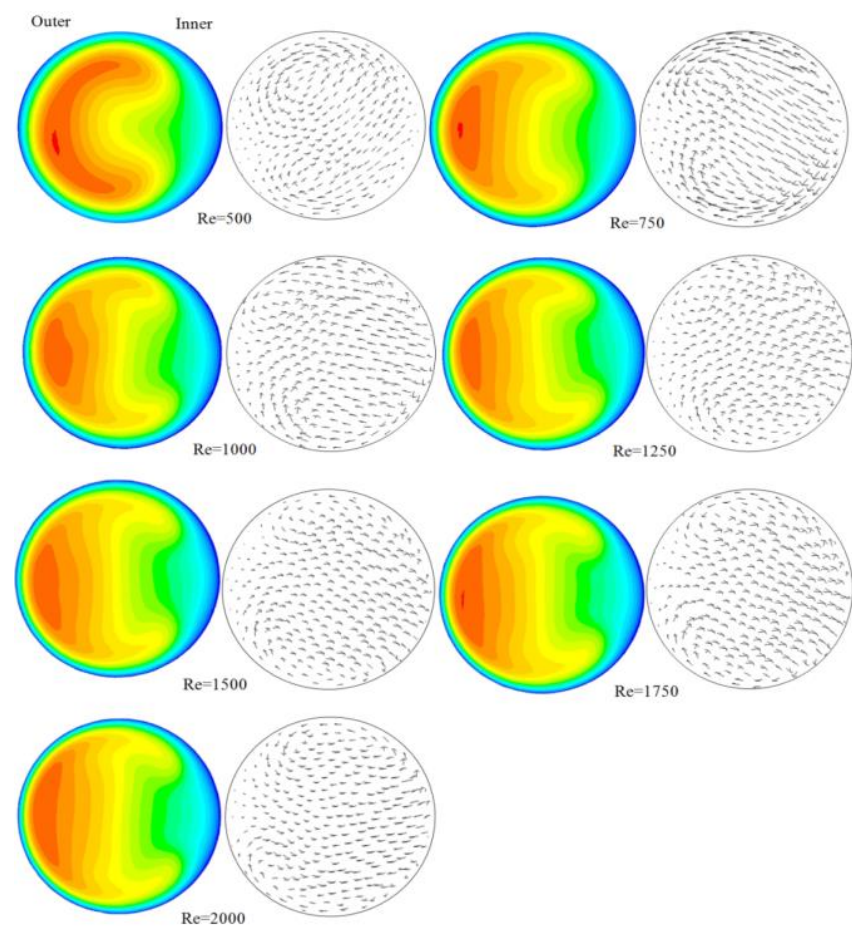

Figure 14. Velocity contours and vectors of the first plane for $\mathrm{P}=0.05 \mathrm{~m}$

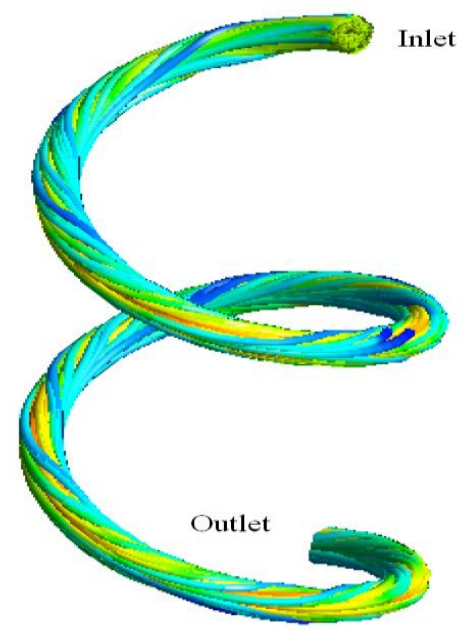

Figure 15. Flow streamlines for $\mathrm{P}=0.05 \mathrm{~m}$

For $\mathrm{P}=0.25 \mathrm{~m}$, however, the velocity contours look quite different in comparison with $\mathrm{P}=0.01 \mathrm{~m}$ and $\mathrm{P}=0.05 \mathrm{~m}$, as shown in Figure 16. It can be said that the effect of the centrifugal forces which cause the secondary flow is highly reduced since the fluid particles that have the maximum velocities remain in the core of the pipe, i.e. are not pushed towards the outer edge of the pipe as happened at $\mathrm{P}=0.01 \mathrm{~m}$ and $\mathrm{P}=0.05 \mathrm{~m}$. Although different Reynolds numbers have been used to investigate the velocity distribution for $\mathrm{P}=0.25 \mathrm{~m}$, the overall velocity appearance of the velocity contours looks the same irrespective of the velocity magnitude, which increases as the Reynolds numbers are increased.

In Figure 17, the flow streamlines deviate slightly from their trajectory path due to the high reduction in the centrifugal forces as the pitch increased. As a result, the secondary flow is weakened more than in the other models $(\mathrm{P}=0.01$ and $\mathrm{P}=0.05)$ and approaches the straight pipe in its behaviour. 


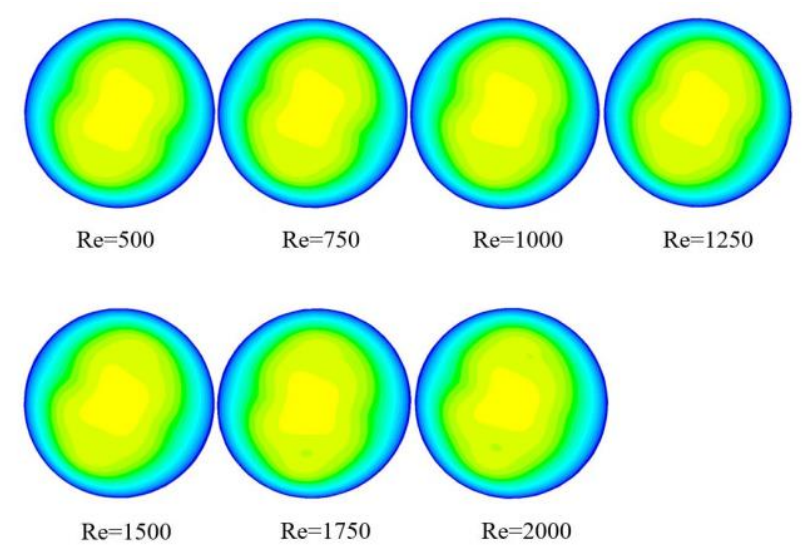

Figure 16. Flow streamlines of the pipe portion in a fully developed area for $\mathrm{P}=0.25 \mathrm{~m}$

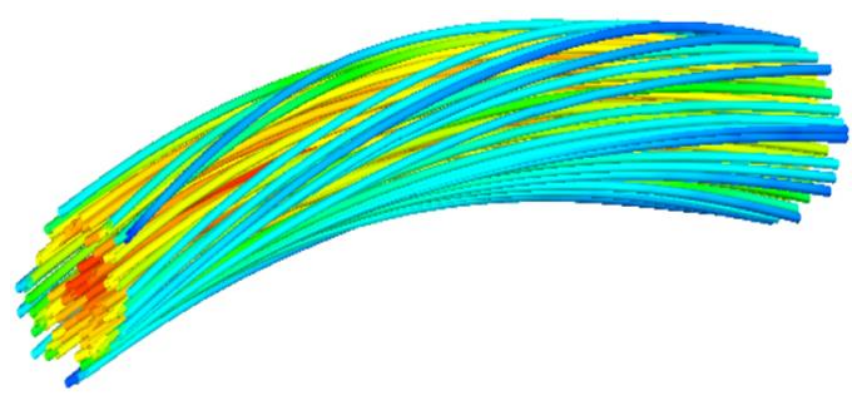

Figure 17. Flow streamlines of the pipe portion in a fully developed area for $\mathrm{P}=0.25 \mathrm{~m}$

One might expect that increasing the pitch from $\mathrm{P}=0.01 \mathrm{~m}$ to $\mathrm{P}=0.05 \mathrm{~m}$ will decrease the maximum pressure through the whole domain, as can be seen in Figure 18, where the maximum pressure dropped from $71 \mathrm{~Pa}$ for $\mathrm{P}=0.01 \mathrm{~m}$ to 68.8 $\mathrm{Pa}$ for $\mathrm{P}=0.05 \mathrm{~m}$, due to the reduction in the coil friction losses and wall shear stress which makes the maximum pressure a little bit lower than its equivalent at $\mathrm{P}=0.01 \mathrm{~m}$.

For $\mathrm{P}=0.25 \mathrm{~m}$, the situation looks different: it can be seen that the maximum pressure for $\mathrm{P}=0.25 \mathrm{~m}$ at the inlet has increased to $101 \mathrm{~Pa}$, i.e. the percentage of increment in the pressure is almost $47 \%$ of $\mathrm{P}=0.05 \mathrm{~m}$. This raises the question of why the maximum pressure increases as the pitch are increased from $\mathrm{P}=0.05 \mathrm{~m}$ to $\mathrm{P}=0.25 \mathrm{~m}$ while keeping the coil and pipe diameters as constants.

The reason is the extra helix length. The extended length of the helix due to the increment in the pitch dimension is the reason for the pressure rising in the inlet region. The length of the helix for $\mathrm{P}=0.25$ is increased by almost $107 \%$ of the helix length of $\mathrm{P}=0.05 \mathrm{~m}$; i.e. the helix length is extended from $0.27 \mathrm{~m}$ for $\mathrm{P}=0.05 \mathrm{~m}$ to $0.56 \mathrm{~m}$ for $\mathrm{P}=0.25 \mathrm{~m}$ and this increment in helix length made the maximum pressure of $\mathrm{P}=0.25 \mathrm{~m}$ rise to $101 \mathrm{~Pa}$ at the inlet, as shown in Figure 18. It can be said that the wall shear stress is in direct proportion to the change in pressure and consequently the wall shear stress for $\mathrm{P}=0.25 \mathrm{~m}$ increases also, but Figure 11 indicates that the wall shear stress is reduced more than its equivalent for $\mathrm{P}=0.01 \mathrm{~m}$ and $\mathrm{P}=0.05 \mathrm{~m}$, despite the increment in the pressure drop between the planes. In fact, the reason behind this reduction in wall shear stress values for $\mathrm{P}=0.25 \mathrm{~m}$ is the distance between the planes, which plays a significant role in the determination of the wall shear stress.
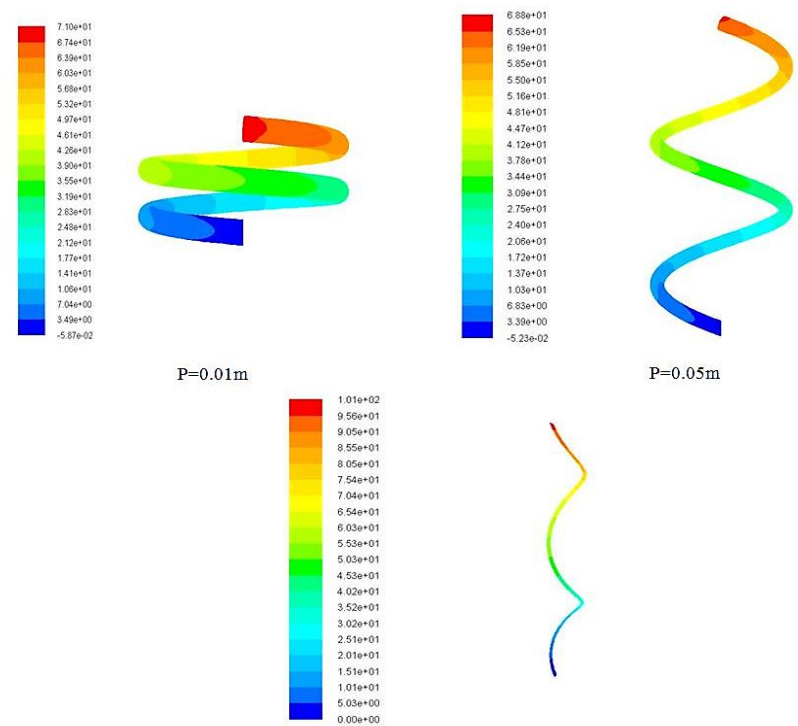

$\mathrm{P}=0.05 \mathrm{~m}$

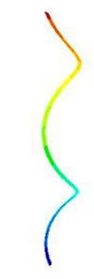

$\mathrm{P}=0.25 \mathrm{~m}$

Figure 18. Pressure contours for different pitch arrangement

\section{CONCLUSION}

In this paper, the influence of changing the pitch size was investigated by testing three different models in laminar flows. This investigation was done through the observation of the coil friction factor profile, wall shear stress, and velocity-pressure contours. The results clearly showed that the first model $(\mathrm{P}=0.01 \mathrm{~m})$ yielded good results and these results have been validated with Ito's equation. The helical coil behaviour for the first model closely resembles a toroidal pipe in its conductance. Cioncolini and Santini (2006) [1] stated that Ito's equation can be used even for $\mathrm{P}=0.025 \mathrm{~m}$ and gives an acceptable result. In the results for the second model $(\mathrm{P}=0.05 \mathrm{~m})$, it was noticed that the overall trend was not markedly different compared to the first model, other than in magnitudes. With a large pitch configuration $(\mathrm{P}=0.25 \mathrm{~m})$, a sharp decrease in the coil friction factor and wall shear stress was detected, in addition to a complete transformation in the shape of the velocity contours, since the centrifugal forces were exceedingly reduced. A comparison was done between the third model $(\mathrm{P}=0.25 \mathrm{~m})$ and Hagen-Poiseuille resistance formula for a straight pipe to observe how the third model was approximately similar to the straight pipe in its behaviour. In terms of velocity contours, for $(\mathrm{P}=0.05 \mathrm{~m})$, the overall form of the velocity contours appears to be more bent in comparison with other Reynolds numbers, while the other velocity contours do not look very different from the equivalent for $\mathrm{P}=0.01$. For $\mathrm{P}=0.25 \mathrm{~m}$, however, the velocity contours look quite different in comparison with $\mathrm{P}=0.01 \mathrm{~m}$ and $\mathrm{P}=0.05 \mathrm{~m}$.

\section{ACKNOWLEDGMENT}

Authors would like to present my loyal thanks to my supervisor Dr Andrea Cioncolini for his endless support and encouragement in addition to reviewing the research paper and making various invaluable proposals, without which I would not have been able to finish the research paper. 


\section{REFERENCES}

[1] Cioncolini, A., Santini, L. (2006). An experimental investigation regarding the laminar to turbulent flow transition in helically coiled pipes. Experimental Thermal and Fluid Science, 30(4): 367-380. https://doi.org/10.1016/j.expthermflusci.2005.08.005

[2] Ito, H. (1987). Flow in curved pipes. JSME International Journal, 30(262):

543-552. https://doi.org/10.1017/S0022112096008956

[3] De Amicis, J., Cammi, A., Colombo, L.P., Colombo, M., Ricotti, M.E. (2014). Experimental and numerical study of the laminar flow in helically coiled pipes. Progress in Nuclear Energy, 76: 206-215. https://doi.org/10.1016/j.pnucene.2014.05.019

[4] Austen, D.S., Soliman, H.M. (1988). Laminar flow and heat transfer in helically coiled tubes with substantial pitch. Experimental Thermal and Fluid Science, 1(2): $183-194$ 1777(88)90035-0

[5] Jayakumar, J.S., Mahajani, S.M., Mandal, J.C., Iyer, K.N., Vijayan, P.K. (2010). CFD analysis of single-phase flows inside helically coiled tubes. Computers \& Chemical Engineering, 34(4): 430-446. https://doi.org/10.1016/j.compchemeng.2009.11.008

[6] Jayakumar, J.S. (2012). Helically Coiled Heat Exchangers. INTECH Open Access Publisher. https://doi.org/10.5772/22242

[7] Rogers, G.F.C., Mayhew, Y.R. (1964). Heat transfer and pressure loss in helically coiled tubes with turbulent flow. International Journal of Heat and Mass Transfer, 7(11): $1207-1216$ http://dx.doi.org/10.1016/00179310(64)90062-6

[8] Wilson, E.E. (1915). A basis for rational design of heat transfer apparatus. The J. Am. Soc. Mech. Engrs., 37: 546-551.

[9] Kreith, F., Margolis, D. (1958). Heat transfer and friction in swirling turbulent flow. Heat Transfer and Fluid Mechanics Institute, Stanford University Press, 126-142.

[10] Kirpikov, A.V. (1957). Heat transfer in helically coiled pipes. Trudi. Moscov. Inst. Khim. Mashinojtrojenija, 12: 43-56.

[11] Bai, B., Guo, L., Feng, Z., Chen, X. (1999). Turbulent heat transfer in a horizontal helically coiled tube. Heat Transfer-Asian Research: Co-sponsored by the Society of Chemical Engineers of Japan and the Heat Transfer Division of ASME, 28(5): 395-403. http://dx.doi.org/10.1002/(SICI)15231496(1999)28:5\%3C395::AID-HTJ5\%3E3.0.CO;2-Y

[12] Seban, R.A., McLaughlin, E.F. (1963). Heat transfer in tube coils with laminar and turbulent flow. International journal of Heat and Mass Transfer, 6(5): 387-395. http://dx.doi.org/10.1016/0017-9310(63)90100-5

[13] Mori, Y., Nakayama, W. (1967). Study on forced convective heat transfer in curved pipes: (3rd report, theoretical analysis under the condition of uniform wall temperature and practical formulae). International Journal of Heat and Mass Transfer, 10(5): 681-695. http://dx.doi.org/10.1016/0017-9310(67)90113-5

[14] Yamamoto, K., Yanase, S., Yoshida, T. (1994). Torsion effect on the flow in a helical pipe. Fluid Dynamics Research, 14(5): 259-273. http://dx.doi.org/10.1016/0169-5983(94)90035-3

[15] Yamamoto, K., Akita, T., Ikeuchi, H., Kita, Y. (1995).
Experimental study of the flow in a helical circular tube. Fluid Dynamics Research, 16(4): 237-249. http://dx.doi.org/10.1016/0169-5983(95)00022-6

[16] Yamamoto, K., Aribowo, A., Hayamizu, Y., Hirose, T., Kawahara, K. (2002). Visualization of the flow in a helical pipe. Fluid Dynamics Research, 30(4): 251-267. http://dx.doi.org/10.1016/S0169-5983(02)00043-6

[17] Austen, D.S., Soliman, H.M. (1988). Laminar flow and heat transfer in helically coiled tubes with substantial pitch. Experimental Thermal and Fluid Science, 1(2): 183-194. http://dx.doi.org/10.1016/08941777(88)90035-0

[18] Siegel, R., Sparrow, E.M., Hallman, T.M. (1958). Steady laminar heat transfer in a circular tube with prescribed wall heat flux. Applied Scientific Research, Section A, 7(5): 386-392. http://dx.doi.org/10.1007/BF03184999

[19] Manlapaz, R.L., Churchill, S.W. (1981). Fully developed laminar convection from a helical coil. Chemical Engineering Communications, 9(1-6): 185-200. http://dx.doi.org/10.1080/00986448108911023

[20] Abul-Hamayel, M.A. (1979). Heat transfer in helically coiled tubes with laminar flow. Doctoral dissertation, Oklahoma State University.

[21] Ali, S. (2001). Pressure drop correlations for flow through regular helical coil tubes. Fluid Dynamics Research, 28(4): 295-310. https://doi.org/10.1016/S0169-5983(00)00034-4

[22] Sikandar, M.U. (2019). Design of helical coil heat exchanger for a mini powerplant. International Journal of Scientific and Engineering Research, 10(12): 303-313. https://doi.org/10.14299/ijser.2019.12

[23] Kedzierski, M., Kim, M.S. (1996). Single-phase heat transfer and pressure drop characteristics of an integralspine fin within an annulus. Journal of Enhanced Heat Transfer, 3(3): 201-210. https://doi.org/10.1615/JEnhHeatTransf.v3.i3.40

[24] White, C.M. (1929). Streamline flow through curved pipes. Proceedings of the Royal Society of London. Series A, Containing Papers of a Mathematical and Physical Character, 123(792): 645-663. https://doi.org/10.1098/rspa.1929.0089

[25] White, C.M. (1932). Fluid friction and its relation to heat transfer. Trans. Inst. Chem. Eng. (London), 10, 66-86.

[26] Prandtl, L. (1953). Essentials of fluid dynamics: with applications to hydraulics, aeronautics, meteorology and other subjects. Hafner Publishing Company.

[27] Yamamoto, K., Yanase, S., Jiang, R. (1998). Stability of the flow in a helical tube. Fluid Dynamics Research, 22(3): 153-170. http://dx.doi.org/10.1016/S01695983(97)00032-4

[28] Adler, M. (1934). Strömung in gekrümmten Rohren. ZAMM. Journal of Applied Mathematics and Mechanics/Zeitschrift für Angewandte Mathematik und Mechanik, 14(5): 257-275. https://doi.org/10.1002/zamm.19340140502

[29] Hasson, D. (1955). Streamline flow resistance in coils. Res. Corresp, 1(1).

[30] Itō, H. (1959). Friction factors for turbulent flow in curved pipes. Journal of Basic Engineering, 81(2): 123132. https://doi.org/10.1115/1.4008390

[31] Mishra, P., Gupta, S.N. (1979). Momentum transfer in curved pipes. 1. Newtonian fluids. Industrial \& Engineering Chemistry Process Design and Development, $\quad 18(1)$ : $130-137$. 
https://doi.org/10.1021/i260069a017

[32] Castiglia, F., Chiovaro, P., Ciofalo, M., Liberto, M.D., Maio, P., Piazza, I.D., Vella, G. (2010). Modelling flow and heat transfer in helically coiled pipes. Part 3: Assessment of turbulence models, parametrical study and proposed correlations for fully turbulent flow in the case of zero pitch. Report Ricerca di Sistema Elettrico.

[33] Patankar, S.V., Spalding, D.B. (1983). A calculation procedure for heat, mass and momentum transfer in three-dimensional parabolic flows. Numerical Prediction of Flow, Heat Transfer, Turbulence and Combustion, 5473. http://dx.doi.org/10.1016/B978-0-08-0309378.50013-1

[34] Dean, W.R., Hurst, J.M. (1959). Note on the motion of fluid in a curved pipe. Mathematika, 6(1): 77-85. http://dx.doi.org/10.1112/S0025579300001947 